\title{
Phenolic profile and antioxidant activity of different raisin (Vitis vinifera L.) samples
}

\author{
Chiara Di Lorenzo ${ }^{1}$, Gianfranco Frigerio ${ }^{1}$, Francesca Colombo ${ }^{1}$, Luis Peres de Sousa ${ }^{2}$, Ahmet Altindişli ${ }^{3}$, \\ Mario Dell' Agli ${ }^{1}$, and Patrizia Restani ${ }^{1}$ \\ ${ }^{1}$ Dipartimento di Scienze Farmacologiche e Biomolecolari, Università degli Studi di Milano, via Balzaretti 9, 20133 Milan, Italy \\ ${ }^{2}$ Instituto Politecnico de Beja, Rua Pedro Soares, Apartado 6155, 7800-295, Beja, Portugal \\ ${ }^{3}$ Fakulty of Agriculture, Ege University, Bornova, Izmir 35100, Turkey
}

\begin{abstract}
In the last years, the interest in non-alcoholic grape products, aa potential alternative sources of phenolic compounds, has considerably increased. Raisins are dried grapes largely consumed in the Mediterranean area for the positive pattern of nutrients, and for recent data describing potential benefits on human health. Among the health-promoting substances contained in raisins, flavonoids seem the most interesting. The aim of this study was the application of in vitro methods for the characterization of the phenolic fraction of five samples of raisins, and, in parallel, the evaluation of their antioxidant activity. The methods were: 1) Folin-Cocalteau's assay for the quantification of total polyphenol content; 2) vanillin assay for the measure of flavan-3-ols content; 3) DPPH (1,1,-diphenil-2 - picrylhydrazyl) spectrophotometric assay for the assessment of radical scavenging activity; 4) High Performance Thin Layer Chromatography for separation of phenolic substances and assessment of their antioxidant activity; 5) chromatographic separation and quantification of main active substances was performed by HPLC-DAD. Although raisins showed a high variability in their composition, they can be considered as a promising source of phenolic compounds with a significant antioxidant activity for the human diet.
\end{abstract}

\section{Introduction}

Since the first observations of the "French paradox" [1], several studies have demonstrated the antioxidant and the health promoting effects of phenolic compounds present in wine. At the same time, in epidemiological studies, the consumption of wine has been associated with the reduction, in a J-shaped relationship, of the risk factors for cardiovascular disease and certain cancers, as well as for diabetes and dementia [2]. Nevertheless, recently, the wine market has shown a decreasing trend due to the frequent abuse of alcoholic beverages also by young people; this social problem was faced in December 2009 by WHO with the paper "Strategies to reduce the harmful use of alcohol: draft global strategy". The market situation has stimulated a remarkable interest in non-alcoholic grape products, which could represent an alternative source of phenolic compounds. OIV, in its strategic plan 2015-2019, underlines the importance of "evaluating, in collaboration with the FAO and the WHO, the health aspects, nutritional potential and socio-behavioural factors of all nonalcoholic vine derived products". In fact, the reduction in risk of death from all causes observed with moderate wine intake seems comparable to that observed in consumers of certain fruits, grains and vegetables, which are similarly rich in phenolic compounds. Raisins are dried grapes obtained from different cultivars or varieties of Vitis vinifera L. and widely consumed in the Mediterranean area. About $95 \%$ of raisins are dried "Thomson seedless" (named also "Sultanina") grapes. They are an important source of nutrients such as potassium, magnesium, boron sugars, soluble and insoluble fibers [3]. In addition, raisins are rich sources of a wide variety of polyphenols that are particularly interesting for human health. Among them, the most abundant are flavonols (quercetin and kaempferol derivatives) and phenolic acids (mainly caftaric and coutaric acid). Most of the compounds present in raisins derive from the fresh grapes, but other compounds increase during processing, such as caffeoyl tartaric acid and some quercetin and kaempferol derivatives [3]. In literature, different studies have illustrated the potential health benefits of raisins, such as the increase of feeling of satiety and decrease of food intake, the reduction of low-density lipoprotein (LDL) cholesterol, oxidized LDL and gastric inflammation [5,6]. Furthermore, even though raisins have a long-standing reputation of a food promoting dental caries, new findings have shown that raisins consumption as such does not drop oral $\mathrm{pH}$ and inhibit some of the bacteria responsible for dental caries [7]. Most of the biological effects of raisins are associated to the antioxidant activity, due to the presence of flavonoids, as reported above. On these bases, the study of the phenolic profile and the relative abundance of active compounds is the first critical step in investigating the benefits coming from raisins consumption. The aim of the study was the characterization of the phenolic fraction of five samples of raisin and the assessment of their antioxidant activity by using in vitro fast screening methods. 
Table 1. Raisin samples included in the study and code used

\begin{tabular}{|l|c|}
\hline Samples analysed & CODE \\
\hline Raisin from Portugal & $\mathrm{P}$ \\
\hline Raisin from Turkey & $\mathrm{T}$ \\
\hline Turkish raisins without seeds & Tws \\
\hline Seeds from Turkey raisins & $\mathrm{Ts}$ \\
\hline Commercial raisins 1 & $\mathrm{C} 1$ \\
\hline Commercial raisins 2 & $\mathrm{C} 2$ \\
\hline Commercial raisins 3 & $\mathrm{C} 3$ \\
\hline
\end{tabular}

\section{Materials and methods}

The methods developed for the characterization of the phenolic fraction of raisin samples were based both on spectrophotometric and chromatographic approaches. Fast screening methods included: 1) Folin-Ciocalteau's assay for the quantification of total polyphenol content; 2) vanillin assay for the measure of flavan-3ols content; 3) DPPH (1,1-diphenyl-2-picrylhydrazyl) spectrophotometric assay for the assessment of radical scavenging activity; 4) HPTLC (High Performance Thin Layer Chromatography) for the separation and semiquantitative evaluation of antioxidant property of active compounds. Quantitative analysis of the main flavonoids was performed by HPLC (High Performance Liquid Chromatography) coupled with a diode array detector (DAD).

\subsection{Samples}

Five raisins were included in the study; the corresponding abbreviations used in the paper are listed in Table 1.

Portuguese raisin (variety Early Gold) was a sultanatype seedless from Beja (Portugal) whereas Turkish raisin (variety sultana) was from Izmir, Turkey. Three brands of raisin were from Italian drugstores; the origin of $\mathrm{C} 1$ was not reported in the label, while C2 and C3 were from Australia and Turkey, respectively. Since the macroscopic evaluation of variety from Turkey showed the presence of seeds (Fig. 1), absent in other varieties, they were manually removed and processed at the same conditions of the other samples. Processing procedures were known only for raisins from Izmir and Beja. The former was prepared as follows: after being harvested, grapes were dipped into a solution for removing wax layer of berries. Solution was composed by water, potassium carbonate $5 \%(\mathrm{w} / \mathrm{v})$ and olive oil $1 \%(\mathrm{v} / \mathrm{v})$. Then, grapes were laid on polyethylene sheets and sun-dried for seven days. Portuguese raisins were allowed to dry on the plant for 5 weeks and then harvested.

Raisin were extracted by using hydro-alcoholic (HE) and water (WE) solutions. The investigation of water/ethanol extraction was due to the common occurrence of these extracts as ingredients of food supplements, while water extraction simulated the physiological conditions. About $2 \mathrm{~g}$ of raisins were added with $40 \mathrm{~mL}$ of water:ethanol mixture $(1: 1)$ or $40 \mathrm{~mL}$ of water. Samples were thoroughly homogenized and mixed under stirring for $4 \mathrm{~h}$ in dark conditions at room temperature. Then, the mixtures were filtered in a vacuum flask and $40 \mathrm{~mL}$ of hydro-alcoholic or water solution were added to the solid residue and incubated overnight, as described above. After

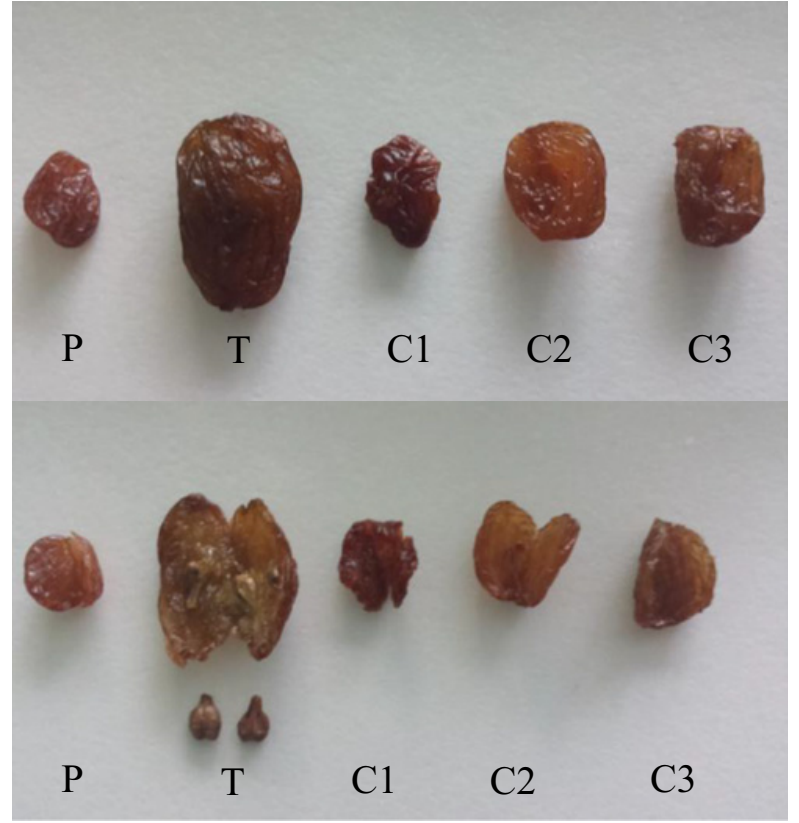

Figure 1. Raisins samples included in the study; $\mathrm{P}=$ Portuguese raisins; $\mathrm{T}=$ Turkish raisins; $\mathrm{C} 1=\mathrm{Commercial}$ raisins 1 ; $\mathrm{C} 2=$ Commercial raisins $2 ; \mathrm{C} 3=$ Commercial raisins 3 . $\mathrm{T}$ showed the presence of seeds (lower panel) [6]

this procedure, supernatants were combined, freeze-dried and stored at $-20^{\circ} \mathrm{C}$ till the use.

\subsection{Spectrophotometric assays}

Three spectrophotometric assays were used in this study.

\subsubsection{Folin-Ciocalteu's assay}

Total polyphenol content (TPC) was determined according to Singleton and Rossi [8].

About $50 \mathrm{mg}$ of freeze-dried samples prepared as described in 2.1 were solubilized in $1 \mathrm{~mL}$ of a 50:50 (v/v) water:methanol solution. Aliquots of $300 \mu \mathrm{L}$ from samples, or water for blank, were mixed in test tubes with: $1.5 \mathrm{~mL}$ of Folin-Ciocalteau's reagent (Sigma Aldrich, Germany) diluted 10 times (v/v), and $1.2 \mathrm{~mL}$ of $7.5 \%$ sodium carbonate (Sigma Aldrich, Germany). After 30 minutes, the absorbance was measured at $765 \mathrm{~nm}$ (UV-visible spectrophotometer, Varian Cary 50 SCAN, Palo Alto, California, U.S.A.). Results were expressed as gallic acid (GA) equivalents (mg/g).

\subsubsection{Vanillin assay}

Total flavan-3-ols content of raisins was determined according to the method described by Price et al. [9]. Samples were prepared as described in 2.1 and diluted with methanol according to the analyte abundance. Catechin was used as a standard. Aliquots of $0.4 \mathrm{~mL}$ of standard catechin solution $(50-300 \mu \mathrm{g} / \mathrm{mL}$ in methanol) or sample or methanol (blank) $1 \mathrm{~mL}$ of $1 \%$ vanillin solution in methanol $(\mathrm{w} / \mathrm{v})$ were mixed with $1 \mathrm{~mL}$ of $9 \mathrm{M} \mathrm{HCl}$ in methanol. To correct the absorbance for the possible interference due to sample characteristics (colour, turbidity, etc.), the same solutions were prepared using 
methanol instead of vanillin reagent. The reaction mixtures were incubated in a water bath for 20 minutes at $30{ }^{\circ} \mathrm{C}$ and the absorbance (A) was measured at $500 \mathrm{~nm}$.

A of samples was obtained according to the following relationship (1):

$$
\mathrm{A}=(\mathrm{As}-\mathrm{Ac})-(\mathrm{Ab}-\mathrm{Ao})
$$

$\mathrm{As}=$ Absorbance of $0.4 \mathrm{~mL}$ sample $+1 \mathrm{~mL} 1 \%$ vanillin $+1 \mathrm{~mL} 9 \mathrm{M} \mathrm{HCl}$

$\mathrm{Ac}=$ Absorbance of $0.4 \mathrm{~mL}$ methanol (blank) $+1 \mathrm{~mL} \mathrm{1 \%}$ vanillin $+1 \mathrm{~mL} 9 \mathrm{M} \mathrm{HCl}$

$\mathrm{Ab}=$ Absorbance of $0.4 \mathrm{~mL}$ sample $+1 \mathrm{~mL}$ methanol $+1 \mathrm{~mL} 9 \mathrm{M} \mathrm{HCl}$

$\mathrm{Ao}=$ Absorbance of $0.4 \mathrm{~mL}$ methanol (blank) $+1 \mathrm{~mL}$ methanol $+1 \mathrm{~mL} \mathrm{9M} \mathrm{HCl}$.

A calibration curve was prepared calculating A for each standard concentration. Results were expressed as catechin equivalents $(\mathrm{mg} / \mathrm{g})$.

\subsubsection{Antioxidant activity by DPPH assay}

The antioxidant activity (AOA) of raisin samples was measured spectrophotometrically, as a measure of radical scavenging activity, using 1,1-diphenyl-2-picryl-hydrazyl free radical (DPPH) $[10,11]$. Samples were prepared as described in 2.1. Aliquots of $1 \mathrm{~mL}$ of DPPH (Sigma Aldrich, Germany) in methanol $(5 \mathrm{mg} / 100 \mathrm{~mL})$ were mixed with $0.5 \mathrm{~mL}$ of each sample suitably diluted. The absorbance was measured after 30 minutes at $517 \mathrm{~nm}$. Results were expressed as equivalents of Trolox (mg/g).

\subsection{Fast chromatographic methods: High Performance Thin Layer Chromatography (HPTLC)}

Thin Layer Chromatography (HPTLC) is a fast and suitable method for screening different classes of molecules, allowing the fingerprint characterization of several botanical products [12]. Furthermore, HPTLC technique can be used for the assessment of biological properties such as, for example, the semi-quantitative measure of antioxidant activity.

In this study, HPTLC technique was used to perform a screening of flavonoids contained in raisin samples evaluating in parallel the associated antioxidant activity.

\subsubsection{Flavonoid profile and antioxidant activity of raisins}

Aliquots of $5 \mu \mathrm{L}$ of standard solutions $(200 \mu \mathrm{g} / \mathrm{mL})$ of the main flavonoids (epigallocatechin-3-O-gallate, epicatechin, catechin, procyanidin $\mathrm{B} 1$, procyanidin $\mathrm{B} 2$, caftaric acid, rutin, hyperoside, quercetin-3-O-glucoside, quercetin-3-O-glucuronide, kaemferol-3-glucoside) were applied on silica gel-plates 254F (10 x $20 \mathrm{~cm}$, Merck, Darmstadt, Germany) by using a semi-automatic applicator. In the case of raisin samples (prepared as described in 2.1) volumes of $15 \mu \mathrm{L}$ were loaded onto the plate. At the end of the chromatographic run, the plate was sprayed with a DPPH (Sigma Aldrich, Germany) methanolic solution $(0.05 \%)$ and dried for $1 \mathrm{~min}$ at room temperature

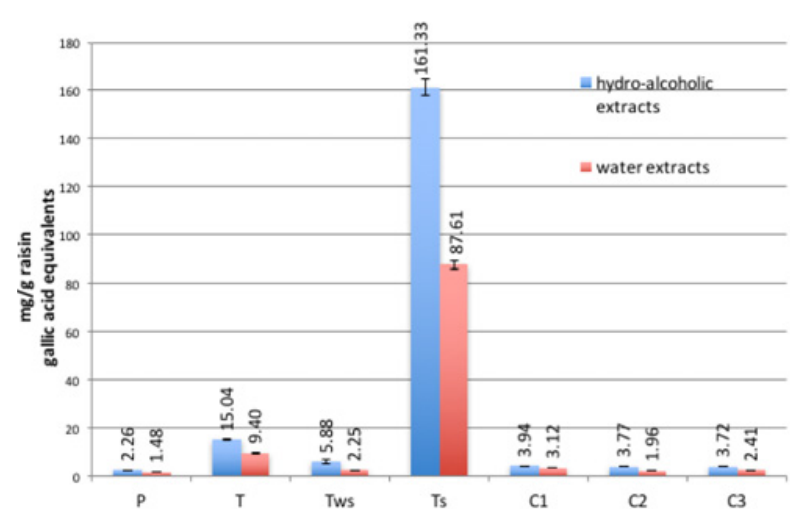

Figure 2. Total phenol content ( $\mathrm{mg} / \mathrm{g}$ of GA equivalents) of raisin hydro-alcoholic (blue bars) and water extracts (red bars). For abbreviations see Table 1 .

in an extractor hood. The dried plate was wrapped with aluminium foil for $30 \mathrm{~min}$ and exposed at UV $(366 \mathrm{~nm})$ or at visible light. The images were achieved by using a specific software (VisionCats, CAMAG, Muttenz, Switzerland).

\subsection{Quantitative analysis by High Performance Liquid Chromatography (HPLC)}

HPLC equipment included a pump (P2000, Thermo Separation products, San José CA, USA), an interface (SN4000, Thermo Separation products, San José, CA, USA), a Diode Array Detector (6000 LP, Thermo Separation products, San José, CA, USA), an injection valve (Rheodyne, Cotati, CA, USA) with a $20 \mu \mathrm{L}$ loop. The method was used for the separation and quantification of the main flavan-3-ols monomers (catechin, epicatechin, epicatechin-3-O-gallate), dimers (procyanidin B1,B2, B3) and trimers (procyanidin C1), phenolic acids (caftaric acid), and flavonols (rutin, hyperoside, quercetin3-O-glucoside, quercetin-3-O-glucuronide, kaemferol-3glucoside).

Stock solutions (Sigma Aldrich, Germany) were prepared in methanol:water $(50: 50, \mathrm{v} / \mathrm{v})$ at the final concentration of $200 \mu \mathrm{g} / \mathrm{mL}$. Solutions were diluted with $0.1 \mathrm{~N} \mathrm{HCl}$ to obtain the working solutions ranging between 0.1 and $25 \mu \mathrm{g} / \mathrm{mL}$.

The chromatographic column was a $4 \mathrm{u}$ Synergi MAXRP 80A $(250 \times 2.0 \mathrm{~mm}, 4 \mu \mathrm{m}$; Phenomenex, Torrance, CA, USA).

The analysis was performed using a gradient elution at a flow rate of $0.3 \mathrm{~mL} / \mathrm{min}$, where $\mathrm{A}$ was a mixture of water:acetonitrile:formic acid 96.9:3:0.1 (v/v/v); and B a mixture of acetonitrile:water:formic acid 50:49.9:0.1 $(\mathrm{v} / \mathrm{v} / \mathrm{v})$. The detection was at $360 \mathrm{~nm}$ for flavonols and at 280 for caftaric acid and flavan-3-ols.

The method was validated according to the FDA Guidelines on Bioanalytical Methods Validation [13] and recently published $[3,14]$.

\section{Results and discussion}

\subsection{Spectrophotometric assays}

Figure 2, Figs. 3 and 4 show the total polyphenol content, total flavan-3-ols content and the antioxidant activity of hydro-alcoholic and water raisin extracts, respectively. 


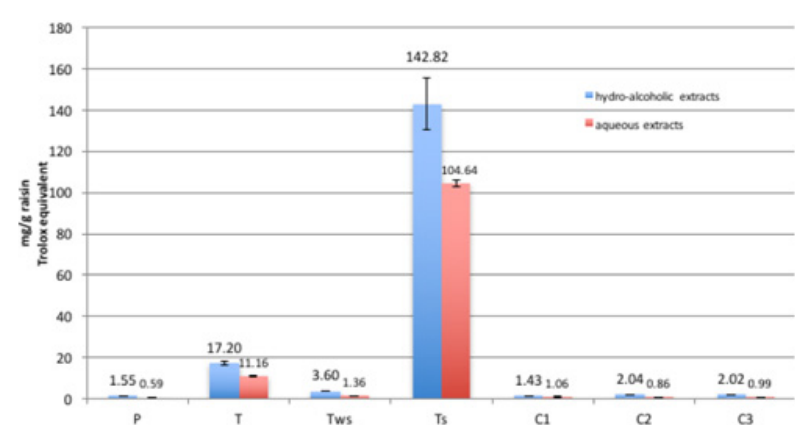

Figure 3. Antioxidant activity ( $\mathrm{mg} / \mathrm{g}$ of Trolox equivalents), of raisin hydro-alcoholic (blue bars) and water extracts (red bars). For abbreviations see Table 1 .

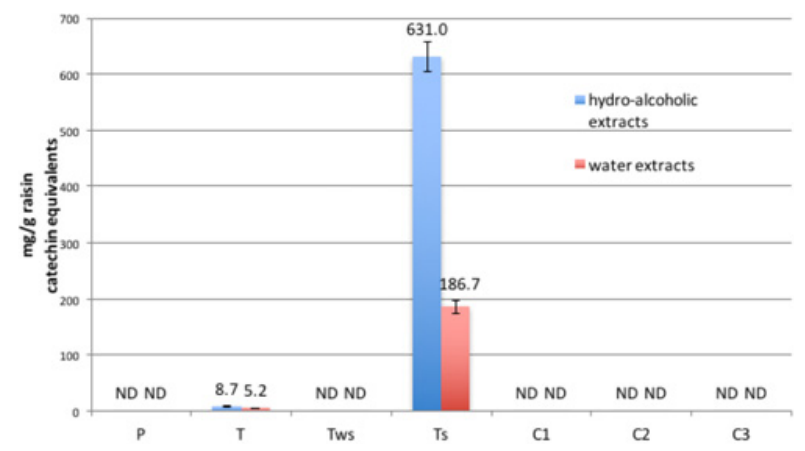

Figure 4. Total flavan-3-ols content (mg/g catechin equivalents), of raisin hydro-alcoholic (blue bars) and water extracts (red bars). For abbreviations see Table 1.

Figure 2 shows that the total phenolic content (TPC) of hydro-alcoholic extracts (HE) was higher than that measured in samples extracted in water (WE). It ranged between $2.26 \pm 0.12$ and $161.33 \pm 3.63 \mathrm{mg}$ GA equivalents/g raisins (mean \pm s.d.) for $\mathrm{HE}$ and $1.48 \pm 0.11$ and $87.61 \pm 1.82 \mathrm{mg} \mathrm{GA}$ equivalents/g raisins (mean \pm s.d.) for WE. The highest TPC was found in raisin from Turkey, where the total phenol content was 3-6 fold higher than the other samples, while the lowest amount of phenols was detected in Portuguese raisin extract. This was due to the presence of the seeds, according to data from the literature [15].

Samples with the most abundant phenol content showed also the highest antioxidant activity (Fig. 3).

Both hydro-alcoholic and water extracts from Turkey showed the highest antioxidant activity (142.82 \pm $12.52 \mathrm{mg} / \mathrm{g}$ and $104.64 \pm 1.54 \mathrm{mg} / \mathrm{g}$ Trolox equivalents, respectively), followed by commercial raisins $\mathrm{C} 2$ and $\mathrm{C} 3$ $(2.04 \pm 0.13 \mathrm{mg} / \mathrm{g}$ and $2.02 \pm 0.10 \mathrm{mg} / \mathrm{g}$ Trolox equivalents, respectively). The high antioxidant activity of the seeds from Turkish raisins was attributed to the presence of significant amounts of flavan-3-ols, particularly procyanidins, as previously described [16]. The positive effects on human health of grapes and grape seeds extracts are mainly attributed to this class of compounds [5]. Another interesting result was the optimal linear relationship between the antioxidant activity and total phenol content of both hydro-alcoholic and water extracts $\left(\mathrm{R}^{2}=0.99857\right.$ and $\mathrm{R}^{2=} 0.99948$, respectively). The presence of high amounts of flavan-3-ols was confirmed by the vanillin assay (Fig. 4), widely used for quantitative analysis of flavanols, thanks to its specificity and sensitivity. Total flavan-3-

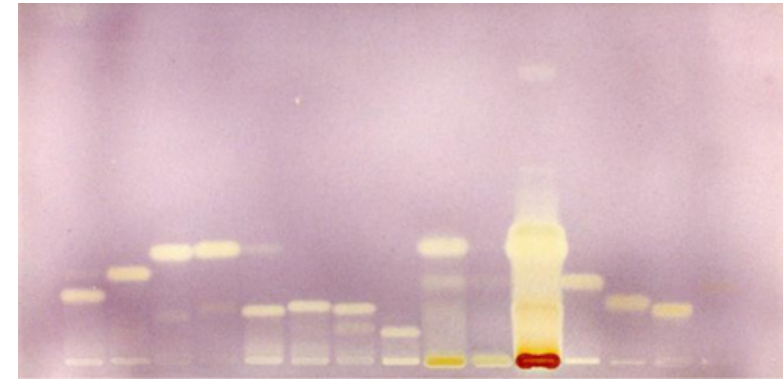

$\begin{array}{llllllllllllll}\text { EGCG ECG } & \text { EC } & \text { C } & \text { B1 } & \text { B2 } & \text { B3 } & \text { C1 } & \text { T } & \text { Tws } & \text { Ts } & \text { CA } & \text { Qg } & \text { H } & \text { Kg }\end{array}$
EGCG: epigallocatechin3-Ogallate

ECG: epicatechin-3-Ogallate

EC: epicatechin

C: catechin

B1: procyanidin B1

B2: procyanidin $\mathrm{B} 2$

B3: procyanidin $\mathrm{B} 3$

C1: $\quad$ procyanidin $\mathrm{C} 1$
T: Turkish raisin extract (whole fruit)

Tws: Turkish raisin extract without seeds

Ts: Turkish raisin extract from seeds

CA: caftaric acid

Qg: quercetin-3-O-glucoside

$\mathrm{H}$ : hyperoside

Kg: kaempferol-3-O-glucoside
Figure 5. HPTLC patterns of hydro-alcoholic extract samples of Turkish raisin.

ols content was calculated using the calibration curve based on catechin as a reference standard $(\mathrm{y}=0.0017 \mathrm{x}+$ $\left.0.0208 ; \mathrm{R}^{2}=0.985\right)$. Results were expressed as catechin equivalents $(\mathrm{mg} / \mathrm{g})$.

The assay allowed to show that only the Turkish extracts, in particular those from the seeds, contained flavan-3-ols, not detectable in the other samples.

\subsection{High Performance Thin Layer Chromatography (HPTLC)}

The HPTLC technique allowed a parallel evaluation of antioxidant activity and flavonoid distribution in raisins samples.

\subsubsection{Flavonoid pattern and antioxidant activity of raisins samples}

The innovative approach of HPTLC technique allowed the correlation of flavonoid pattern of samples with the relative antioxidant activity. For the evaluation of the antioxidant activity, the plates were exposed at $366 \mathrm{~nm}$ or visible light after derivatization with the DPPH solution. As an example, Fig. 5 shows the flavonoid distribution and the associated antioxidant activity of Turkish raisins.

The derivatization with DPPH solution and exposure of the plate at visible light, showed that flavan-3-ols, (e.g. catechin and epicatechin) were the most abundant compounds (mainly in the seeds and in the whole fruit) with the highest antioxidant activity. Procyanidins were detectable both in $\mathrm{T}$ and in $\mathrm{Ts}$, showing an important antioxidant activity as well. A similar pattern was observed in water extracts, although, as expected, they showed a lower abundance of flavonoids, probably due to the lower extraction efficiency of water (Fig. 6). Flavan-3-ols were not visible in the other samples (data not shown). 


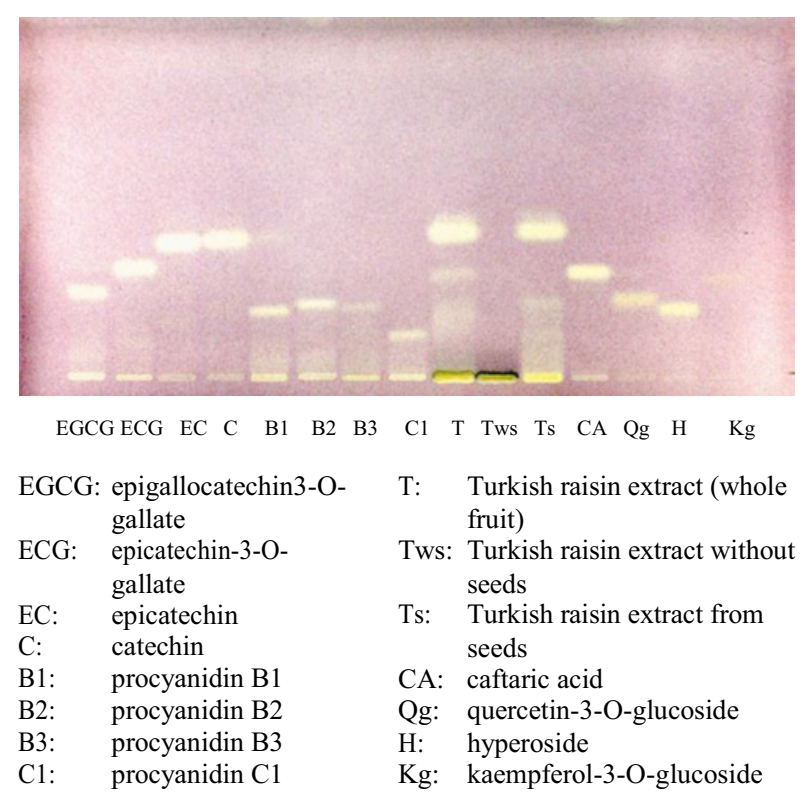

Figure 6. HPTLC patterns of water extract samples of Turkish raisin.

Table 2. Content of flavan-3-ols $(\mu \mathrm{g} / \mathrm{g} \pm \mathrm{s} . \mathrm{d})$ in Turkish raisins (HE).

\begin{tabular}{|c|c|c|}
\hline Flavan-3-ols & T (whole fruit) & Ts (seeds) \\
\hline Catechin & $615.33 \pm 42.84$ & $10231.06 \pm 89.38$ \\
\hline Epicatechin & $148.14 \pm 13.43$ & $3201.16 \pm 156.90$ \\
\hline $\begin{array}{c}\text { Epicatechin-3-O- } \\
\text { gallate }\end{array}$ & $10.86 \pm 0.34$ & $300.50 \pm 7.11$ \\
\hline $\begin{array}{c}\text { Epigallocatechin- } \\
\text { 3-O-gallate }\end{array}$ & $4.94 \pm 0.22$ & $19.45 \pm 0.62$ \\
\hline Procyanidin B1 & $345.46 \pm 15.43$ & $1690.27 \pm 76.26$ \\
\hline Procyanidin B2 & $41.82 \pm 2.16$ & $579.60 \pm 51.79$ \\
\hline Procyanidin B3 & $138.93 \pm 9.03$ & $1684.81 \pm 34.85$ \\
\hline Procyanidin C1 & $14.00 \pm 1.24$ & $703.27 \pm 4.85$ \\
\hline
\end{tabular}

\subsection{High Performance Liquid Chromatography (HPLC)}

The HPLC-DAD method, developed to quantify the main flavonoids, was validated according to the FDA guidelines [12] and the main parameters have been recently published [6]. The results obtained show that the method is precise, sensitive and capable of separating satisfactorily the searched compounds. Flavan-3-ols were not detectable in raisin samples, apart from Turkish raisins (whole fruits and seeds), confirming the results obtained by HPTLC analysis. As an example, Fig. 7 illustrates the chromatograms of $\mathrm{P}$ and $\mathrm{T}$ hydro-alcoholic extracts after detection at $280 \mathrm{~nm}$ and $360 \mathrm{~nm}$.

Tables 2 and 3 list the amounts of flavan-3-ols in hydroalcoholic and water extracts of Turkish raisins (whole fruit and seeds), respectively.

As shown by HPTLC analysis, catechin and epicatechin were the most abundant compounds (particularly in the seeds), followed by procyanidins B1 and B3. As reported in the literature, all these compounds contribute to some positive effects on human health, such as antioxidant and anti-inflammatory activities $[14,18]$. Indeed, procyanidins have shown to inhibit Interleukin-8 release at gastric level [6]. Interestingly, also water extracts showed important levels of flavan-3-ols, suggesting that
Table 3. Content of flavan-3-ols $(\mu \mathrm{g} / \mathrm{g} \pm \mathrm{s} . \mathrm{d})$ in Turkish raisins (WE).

\begin{tabular}{|c|c|c|}
\hline Flavan-3-ols & T (whole fruit) & Ts (seeds) \\
\hline Catechin & $772.44 \pm 33.64$ & $6163.67 \pm 411.75$ \\
\hline Epicatechin & $150.22 \pm 4.74$ & $2169.05 \pm 161.91$ \\
\hline $\begin{array}{c}\text { Epicatechin-3-O- } \\
\text { gallate }\end{array}$ & $4.26 \pm 0.18$ & $119.34 \pm 11.07$ \\
\hline $\begin{array}{c}\text { Epigallocatechin- } \\
\text { 3-O-gallate }\end{array}$ & $71.19 \pm 0.70$ & $154.89 \pm 16.72$ \\
\hline Procyanidin B1 & $78.09 \pm 5.13$ & $2249.84 \pm 178.76$ \\
\hline Procyanidin B2 & $69.70 \pm 2.68$ & $1076.34 \pm 116.16$ \\
\hline Procyanidin B3 & $80.71 \pm 2.58$ & $1073.98 \pm 21.83$ \\
\hline Procyanidin C1 & $15.63 \pm 1.63$ & $426.95 \pm 34.84$ \\
\hline
\end{tabular}

positive effects could occur after the consumption of raisins within the normal diet. Figures 8 and 9 show the HPLC pattern of the other phenol compounds.

Caftaric acid, quercetin-3-O-glucoside and kaempferol3-O-glucoside were the most abundant phenols present in the hydro-alcoholic extracts; in particular, caftaric acid ranged between $24.92 \pm 1.50 \mu \mathrm{g} / \mathrm{g}(\mathrm{C} 1)$ and $74.93 \pm 2.27$ $\mu \mathrm{g} / \mathrm{g}(\mathrm{C} 2)$. These results are consistent with other studies, reporting that, if compared with fresh grapes, raisins show higher levels of some flavonoids (such as organic acids and flavonols), due to the removal of water during drying $[4,17]$. It is noteworthy that Portuguese sample was particularly rich in quercetin-3-O-glucoside $(21.68 \pm 0.91$ $\mu \mathrm{g} / \mathrm{g})$ and kaempferol-3-O-glucoside (16.81 $\pm 0.49 \mu \mathrm{g} / \mathrm{g})$. This could be due to the unusual drying procedure of the raisin (on the plant) that may protect these classes of phenol compounds from oxidation processes [4]. Rutin is one of the bioactive compounds present in significant amount in plants. However, according to previous studies $[3,4]$, the levels of rutin concentration in raisins was very low and ranged between not detectable $(<$ Limit of Detection of $4.3 \pm 0.3 \mathrm{ng} / \mathrm{mL}$ ) to $5.58 \pm 0.17 \mu \mathrm{g} / \mathrm{g}$ of raisins.

Water extracts showed a flavonoid pattern similar to hydro-alcoholic extracts; some compounds showed lower concentration, such as caftaric acid and rutin, mainly in the seeds, where only hyperoside was detectable. Interestingly, if compared with hydro-alcoholic extracts, quercetin-3glucuronide was more represented, probably because of the higher solubility of this compound in aqueous medium.

\section{Conclusions}

This study describes the optimization of some analytical methods to characterize the phenolic fraction of raisins. These methods allowed a fast quantification of the main polyphenols and the evaluation of the associated antioxidant activity. Data obtained by spectrophotometric methods were compared with those deriving from chromatographic analysis in HPLC-DAD. Spectrophotometric methods, although not always specific, were useful to obtain preliminary information about phenolic composition of raisins samples, and were satisfactorily correlated with their antioxidant activity. The HPTLC showed interesting results not only for the screening of active compounds, but also for the evaluation of the antioxidant activity associated with each molecule (other in vitro antioxidant assays determine only the total activity). 

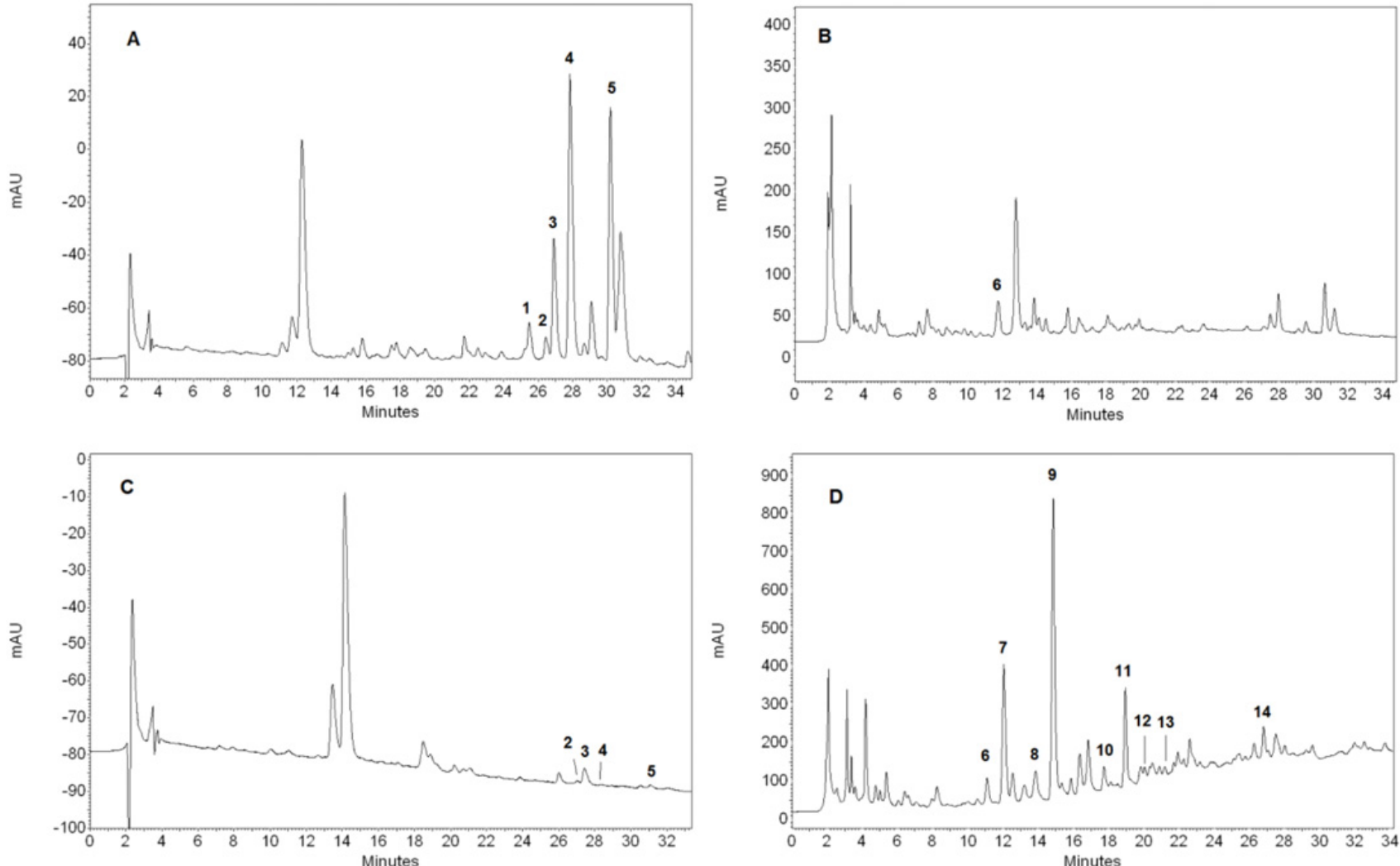

Figure 7. HPLC profile of Portuguese and Turkish HE extracts. Panel A: P raisins revealed at $360 \mathrm{~nm}$; panel B: P raisins revealed at $280 \mathrm{~nm}$; panel C: Turkish raisins revealed at $280 \mathrm{~nm}$; panel D: Turkish raisins revealed at $280 \mathrm{~nm}$. 1-rutin; 2-hyperoside; 3-quercetin-3-Oglucoside; 4-quercetin-3-O-glucuronide; 5-kaempferol-3-O-glucoside; 6-caftaric acid; 7-prcyanidin B1; 8-procyanidin B3; 9-catechin; 10-procyanidin B2; 11-epicatechin; 12-epigallocatechin-3-O-gallate; 13-procyanidin C1; 14- epicatechin-3-O-gallate.

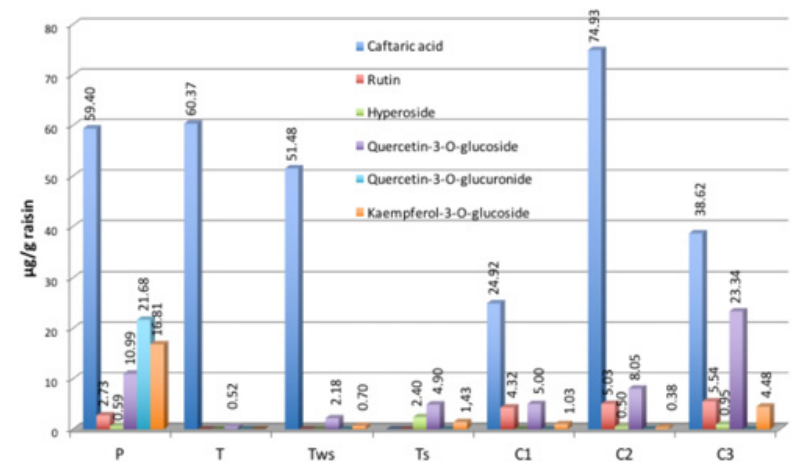

Figure 8. HPLC profile of caftaric acid and flavonols in raisin samples (HE). For abbreviations see Table 1.

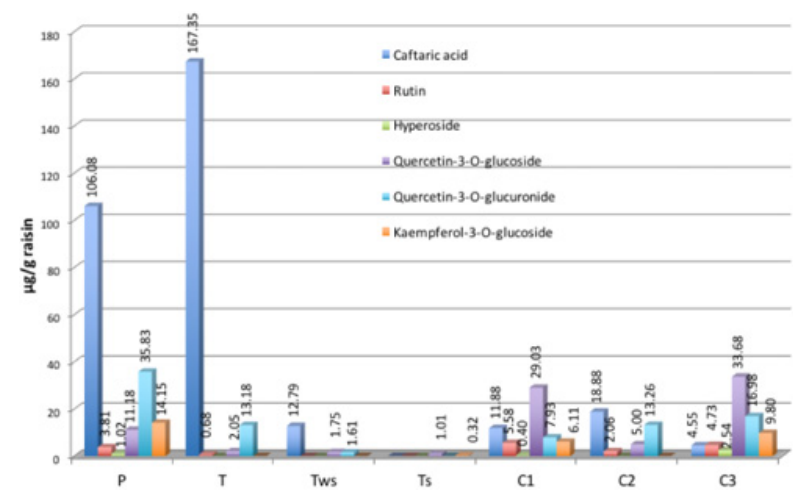

Figure 9. HPLC profile of caftaric acid and flavonols in raisin samples (WE). For abbreviations see Table 1.
HPLC-DAD analysis showed a wide variability in terms of qualitative/quantitative composition. Caftaric acid and quercetin-3-O-glucoside were present in all the varieties assayed, according to the literature data, where is reported that these compounds are not generally affected by drying [4]. The presence of the seeds in Turkish raisins made them particularly rich in catechins and procyanidins, compounds that generally are affected by oxidative reactions occurring during drying, independently of the kind of procedure used $[4,19]$. In this study, only the processing procedures of Turkish and Portuguese raisins were known: the former were sun-dried after dipping processing, while the latter were dried on the plant. However, all the raisin samples showed an interesting phenolic profile. In particular, Turkish raisins could be used in food market as an ingredient of plant food supplements (hydro-alcoholic extract) or of snacks, mixed up with cereals, that could reduce the perceptions of the seeds. Taken together, these preliminary results confirm that raisins contain, in different amount, phenolic substances with significant antioxidant activity, supporting their positive role in the human diet.

The analytical methods described in this work were partially developed in the framework of the European Project PlantLIBRA, funded by the European Community's Seventh Framework Programme (FP7/2007-2013) under Grant agreement no. 245199. This paper does not necessarily reflect the Commission views of its future policy on this area. 


\section{References}

[1] S.C. Renaud, M.De Lorgeril, Lancet 339, 1523 (1992)

[2] N.C Briggs, R.S. Levine, L.D. Bobo, W.P. Haliburton, E.A. Brann, C.H. Hennekens, Am. J. Epidemiol. 156, 454 (2002)

[3] A. Carughi, Health Benefits of Sun-Dried Raisins, health Research and Studies Center: Kingsburg, CA, USA, 2009

[4] F. Karendiz, R.W. Durst, R.E. Wrolstad, J. Agric. Food Chem. 48, 5343 (2000)

[5] B.P. Patel, N. Bellissimo, B. Luhovvyy, L.J. Bennet, E. Hurton, J.E. Painter, G.H. Anderson, Appl. Physiol. Nutr. Metab. 35, 475 (2011)

[6] C. Di Lorenzo, E. Sangiovanni, M. Fumagalli, E. Colombo, G. Frigerio, F. Colombo, L. Peres de Sousa, A. Altindişli, P. Restani, M. Dell'Agli, Int. J. Mol. Sci. 17, 1156 (2016)

[7] A. Wong, D.A. Young, D.E. Emmanouil, L.M. Wong, A.R. Waters, M.T. Booth, J. Food Sci. 78, A26 (2013)

[8] V. L. Singleton, J.A. Rossi, Am. J. Enol. Viticult. 16, $144(1965)$

[9] M.L. Price, S. Van Scoyoc, L.G. Butler, J. Agric. Food Chem. 26, 1214 (1978)

[10] W. Brand-Williams, M.E. Cuvelier, C. Berset, Food Sci. Technol. 28, 25 (1995)
[11] L.P. Leong, G. Shui. Food Chem. 76, 69 (2002)

[12] E. Reich, A. Schibli, 2006. High Performance ThinLayer Chromatography for the Analysis of Medicinal Plants (CIC Edizione internazionale, 2006)

[13] FDA, Food and Drug Administration, Guide for Industry - Bioanalytical Method Validation (2013) http://www.fda.gov/downloads/Drugs/ GuidanceComplianceRegulatoryInformation/ Guidances/UCM368107.pdf last consultation September 2016

[14] E. Sangiovanni, C. Di Lorenzo, E. Colombo, F. Colombo, M. Fumagalli, G. Frigerio, P. Restani, M. Dell'Agli, Food Funct. 6, 2453 (2015)

[15] Y. Yilmaz, Z. Goksel, S.S. Erdogan, A. Ozturk, A. Atak, C. Ozer, J. Food Process. Preserv. 39, 1682 (2015)

[16] F. Grases, R.M. Prieto, R.A. Fernandez-Cabot, A. Costa-Bauza, A.M. Sanchez, M. Prodanov, Nutr. J. 14, 94 (2015)

[17] S.H Adam, N. Giribau, N. Kassim, K.E Kumar, M. Brahmayya, A. Arya, N. Salleh, Biomed. Pharmacother 81, 439 (2016)

[18] G. Williamson, A. Carughi, Nutr. Res. 30, 511 (2010)

[19] S. Sèrio, M.D. Rivero-Pèrez, A.C. Correia, A.M. Jordao, M.L. Gonzàlez-San Josè, Cienc. Tèc. Vitivinic. 29, 1 (2014) 